\title{
Potencialidade antagonística detectada em alguns procariotas agentes de biocontrole de enfermidades de plantas
}

\author{
Victor Rafael Barra1; R eginaldo da Silva1; Hélio Glelson M aciel Ferraz; Dirceu M acagnan²; Harllen Sandro A Ives \\ Silva3; A ndréa B ittencourt M oura4; B ernardo de Almeida Halfeld-V ieira5; H enrique L opes M endonça1; J osé R oberto \\ Vieira únior ${ }^{6}$
}

\begin{abstract}
${ }^{1}$ Departamento deFitopatologia, U niversi dade Federal de Viçosa CEP 36570-000 Viçosa-M G, B rasil; ${ }^{2}$ CEFET - Rio Verde - Goiás; ${ }^{3}$ nstituto B iológico deSão Paulo, Campinas-SP, B rasil; ${ }^{4}$ D epartamento de Fitossanidade, UFPel - Pelotas-R S; ${ }^{5}$ E mbrapa Roraima, B oaVista-R R; ${ }^{6} \mathrm{~L}$ aboratório de Proteção de Plantas, UE NF/CCTA , Campos dos G oytacases-RJ; ; ${ }^{E}$ mbrapa R oraima, B oa Vista-R R; ${ }^{6}$ Embrapa/ Centro de Pesquisa A groflorestal de R ondônia., Porto Velho - Rondônia.
\end{abstract}

A utor para correspondência: Reginal do S. Romeiro

Data de chegada: 12/06/2006. A ceito para publicação em: 20/12/2007

1377

\section{RESUMO}

Barra, V. R.; Romeiro, R.S.; Ferraz, H.G.M .; M acagnan, D.; Silva, H. S. A .; M oura, A. B.; Halfeld-V ieira, B. A ; M endonça, H. L.; Vieira Júnior, J. R. Potencialidade antagonística em al guns procariotas agentes de biocontrole de enfermidades de plantas. Summa Phytopathologica, v.34, n.2, p.121-126, 2008

Ao longo de vários anos, no Laboratório de Bacteriologia de Plantas e Controle Biológico (LBPCB) do Departamento de Fitopatologia da Universidade Federal de Viçosa têm-se, sistematicamente, isolado, de rizosfera, rizoplano e filoplano de plantas cultivadas de importância econômica, milhares de procariotas os quais são testados, um a um, como agentes de biocontrole de enfermidades. A grande maioria deles, como esperado, não exibe qualquer potencialidade como agente de biocontrole e é descartada. Alguns poucos são selecionados, através de demorados ensaios de biocontrole experimental tanto em casa de vegetação como em campo. Neste trabalho, mostra-se que muitos dos organismos em estudo, mesmo havendo sido selecionados, principalmente, por induzirem resistência sistêmica na planta alvo, expressam constitutivamente mecanismos de antagonismo microbiano que parecem fazer parte de seu perfil enquanto agentes de biocontrole.

Palavr as-chaves adicionais: Controle biológico, antagonismo microbiano, antibiose, doenças fúngicas, fitobacterioses.

\section{ABSTRACT}

Barra, V. R.; Romeiro, R.S.; Ferraz, H.G.M.; M acagnan, D.; Silva, H. S. A .; M oura, A. B.; Halfeld-Vieira, B. A ; M endonça, H. L.; Vieira Júnior, J. R. A ntagonistic potentiality in prokaryotic biocontrol agents for plant diseases. Summa Phytopathologica, v.34, n.2, p.121-126, 2008

A long several years, at the Laboratory of Plant Bacteriology and Biological Control of the Department of Plant Pathology of the Federal University of Viçosa, thousands of prokaryote isolates have been obtained from the rhizosphere, rhizoplane and phylloplane of economically important plants. Every obtained isolate is tested as biocontrol agents. As expected, the majority does not show any biocontrol potentiality and is discarded. Few are selected through time-consuming experimental biocontrol trials in greenhouse and field. Even being selected mainly for their ability to induce resistance in target plants, many of them constitutively express mechanisms of antagonism against pathogens that seem to be part of their performance while biocontrol agents.

Additional keywords: Biological control, microbial antagonism, antibiosis, fungal diseases, bacterial diseases

0 controle biológico de enfermidades de plantas vem sendo empregado pelo homem, enquanto agricultor, desde a antiguidade até os dias atua $(1,21)$. Entretanto, o uso de microrganismos para 0 biocontrole de enfermidades de plantas, uso este menos especulativo e de forma mais científica e direcionada, parece ter tido início há al gumas décadas apenas.

Hoje, em todo o mundo, há grupos de pesquisa trabalhando com busca, seleção e teste de organismos procariotas de modo a selecionar os mais promissores para promoção de crescimento e, ou, biocontrole de enfermidades.

Neste trabal ho, relatam-se facetas da potencial idade antagonística de alguns procariotas agentes de biocontrole já selecionados no L aboratório de B acteriologia de Plantas e Controle Biológico (LBPCB) do D epartamento de F itopatologia da U niversidade F ederal de Viçosa. 


\section{MATERIAISE MÉTODOS}

Foi investigada a potencialidade antagonística de 43 isolados, já selecionados e testados. Todos os patógenos desafiantes e agentes de biocontrole utilizados pertencem à coleção de microrganismos do L aboratório de B acteriologia de Plantas e Controle Biológico da UFV. A não ser quando especificado, bactérias foram cultivadas em meio 523 (11) e preservadas emulsificadas em glicerina e mantidas a $-80^{\circ} \mathrm{C}$ (7). Fungos foram cultivados em meio de BDA e preservados, também, sob óleo mineral (26). A ctinomicetos foram cultivados, multiplicados e mantidos em meio de extrato de solo-ágar (18).

Origem dos agentes de biocontrole.

Os agentes de biocontrole com os quais se trabalhou (Tabela 1) foram obtidos a partir de plantas sadias ou com baixa incidência de enfermidades e, sempre que possível, nunca antes expostas a defensivos químicos $(3,9,12,15,24,27)$. Sua potencialidade como agentes de controle biológico foi testada e confirmada por inoculações artificiais com patógenos desafiantes em casa de vegetação e, em algumas instâncias, em experimentos em campo onde enfermidades ocorriam espontaneamente. $\mathrm{Na}$ maioria dos casos, assumiu-se que o controle biológico observado ocorreu, principalmente, por indução de resistência, quando a sel eção foi realizada. A Iguns agentes de biocontrole foram identificados em nível de espécie por análise de ácidos graxos da parede celular (fatty-acid analysis) e, ou, por seqüenciamento do gene ribosomal 16S. Rizobactérias sempre foram dispensadas em plantas por microbiolização de sementes e residentes de filoplano por atomização de uma suspensão de propágulos.

Detecção da produção de HCN .

Foi utilizada a metodologia preconizada por Castric \& Castric (4), com modificações real izadas por M acagnan et al . (13). Para a detecção de cianeto, utilizou-se papel de filtro embebido no reativo de Feigl \& A nger (6) e colônias que originaram manchas de coloração marrom, no papel indicador, na região correspondente à sua posição, foram consideradas produtoras de $\mathrm{HCN}$.

Produção de enzimas líticas.

U tilizou-se a metodologia descrita por R enwick et al. (20), em que os antagonistas foram semeados, por ponto, em meio mineral $\left(\mathrm{CaCO}_{3}\right.$ $0,02 \mathrm{~g} ; \mathrm{FeSO}_{4} 7 \mathrm{H}_{2} \mathrm{O} 0,01 \mathrm{~g} ; \mathrm{KCl} 1,71 \mathrm{~g} ; \mathrm{M} \mathrm{gSO}_{4} 7 \mathrm{H}_{2} \mathrm{O} 0.05 \mathrm{~g} ; \mathrm{Na}_{2} \mathrm{HPO}_{4}$ $12 \mathrm{H}_{2} \mathrm{O} 4,11 \mathrm{~g}$ ágar $15 \mathrm{~g}^{-\mathrm{I}^{-1}}$ ) contendo como única fonte de carbono carboximetilcelulose a $0,5 \%$ para a detecção de celulases ou quitina coloidal a $0,08 \%$ para detecção de quitinases. A quitina coloidal foi obtida a partir de quitina não coloidal conforme metodologia de R eid \& O grydziak (19). Placas contendo os antagonistas semeados em meio mineral contendo as diferentes fontes de carbono foram incubadas a $28^{\circ} \mathrm{C}$, por 10 dias para quitinases e por 4 dias para celulases. Isolamentos produtores de quitinases apresentam, após incubação, um halo claro ao redor da colônia contrastando com o restante do meio com aspecto turvo. Para celulases, a superfície do meio foi coberta por uma solução de 0,5\% de vermelho Congo por 90 min. Depois de drenado o excesso, a observação de uma zona amarelo-alaranjada ao redor das colônias indica a produção de celulases.

Detecção da produção de sideróforos.

Toda a vidraria a ser utilizada foi previamente imersa em solução sulfocrômica por 48 h e, após, lavada seguidas vezes em água destilada. Foi escolhida a técnica universal para a detecção de sideróforos desenvolvida por Schwyn \& N eilands (23). Os microrganismos a serem
Tabela 1 - Agentes de controle biológico selecionados, sua natureza e planta alvo.

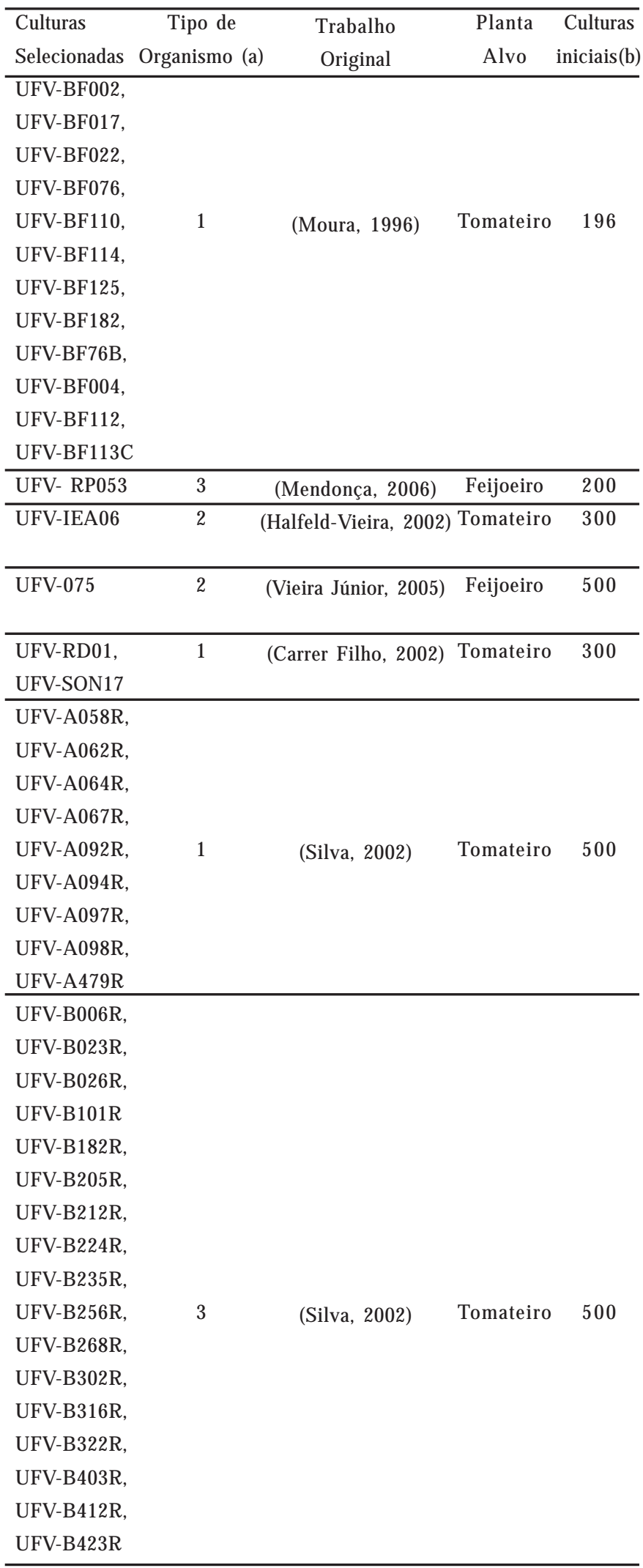

(a) Tipo de organismo: (1) = actinomiceto, isolado como rizobactéria; (2) $=$ residente de filoplano e (3) = rizobactéria.

(b) Culturas iniciais: Número total de isolados quando do início do trabalho 
Tabela 2 - Inibição do crescimento micelial e da germinação de conídios de fungos patogênicos a feijoeiro e tomateiro pelos agentes de biocontrole investigados, em que: $A=S$ clerotinia sclerotiorum; $B=A$ Iternaria solani; $C=$ Verticillium dahliae; $D=V e r t i c i l l i u m$ albo-atrum; $E=S$ clerotium rolfsii; $\mathrm{F}=\mathrm{C}$ orynespora cassiicola; $\mathrm{G}=\mathrm{F}$ usarium oxysporum f.sp lycopersici,

$(-)$ =A usência de inibição, $(+)=$ Presença de inibição e $(a)=\%$ de germinação em relação ao controle, considerado $100 \%$.

\begin{tabular}{|c|c|c|c|c|c|c|c|c|c|c|c|}
\hline \multirow{3}{*}{$\begin{array}{l}\text { A gentes de } \\
\text { Biocontrole }\end{array}$} & \multirow[t]{3}{*}{ Tipo } & \multirow{3}{*}{$\begin{array}{l}\text { Planta } \\
\text { Alvo }\end{array}$} & \multicolumn{9}{|c|}{ Patógenos testados } \\
\hline & & & \multicolumn{6}{|c|}{$\begin{array}{l}\text { Pareamento } \\
\text { de Culturas }\end{array}$} & \multicolumn{3}{|c|}{$\begin{array}{r}\text { Germinação } \\
\text { Esporos } \\
\end{array}$} \\
\hline & & & A & $\mathrm{B}$ & $c$ & $\mathrm{D}$ & $\mathrm{E}$ & & $\mathrm{B}$ & $\mathrm{C}$ & \\
\hline $\mathrm{V}-\mathrm{BF} 002$ & 1 & Tomateiro & & - & + & - & + & & 100 & 18 & 98 \\
\hline 17 & 1 & & & - & + & - & & & 45 & 89 & 96 \\
\hline 22 & 1 & ro & & - & 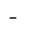 & + & + & & 94 & 91 & 84 \\
\hline 076 & 1 & iro & - & - & + & + & + & & 63 & 2 & 100 \\
\hline 110 & 1 & iro & + & - & + & - & + & & 100 & 100 & 88 \\
\hline 14 & 1 & iro & 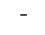 & - & - & - & 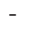 & & 83 & 99 & 100 \\
\hline 25 & 1 & & - & - & - & + & 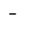 & & 86 & 96 & 89 \\
\hline FV & 1 & & + & & - & + & + & & 100 & 100 & 99 \\
\hline $\mathrm{FV}$ & 1 & & - & - & - & + & + & & 69 & 74 & 95 \\
\hline FV & . & & - & - & - & - & - & & 100 & 6 & 26 \\
\hline & & & + & & - & - & - & & 100 & 88 & 46 \\
\hline & . & & - & - & - & + & + & & 9 & 84 & 80 \\
\hline & 3 & & + & t & + & + & + & & 0 & 4 & 76 \\
\hline & 2 & & - & + & + & - & - & & 8 & 68 & 89 \\
\hline & 2 & & - & - & + & - & - & & 3 & 18 & 9 \\
\hline & & & - & + & - & - & - & - & 5 & 62 & 100 \\
\hline & . & & 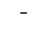 & - & - & - & - & & 0 & 72 & 100 \\
\hline & & & + & - & + & + & + & - & 53 & 39 & 44 \\
\hline & . & & - & - & - & + & + & - & 00 & 100 & 78 \\
\hline & & & - & - & - & - & - & - & 6 & 100 & 100 \\
\hline & . & & - & + & + & - & - & - & 1 & 70 & 6 \\
\hline & 1 & & - & - & - & - & - & - & 6 & 100 & 100 \\
\hline & 1 & & - & - & - & - & - & - & 00 & 89 & 7 \\
\hline & 1 & & - & - & + & - & + & - & 8 & 100 & 100 \\
\hline J & 1 & & - & - & - & - & + & - & 00 & 41 & 6 \\
\hline & 1 & & - & - & - & + & - & & 3 & 81 & 7 \\
\hline & 3 & & + & - & - & - & + & & 2 & 12 & 00 \\
\hline & 3 & & 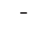 & & - & - & + & & 1 & 4 & 89 \\
\hline & 3 & & 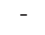 & - & - & - & + & - & 00 & 21 & 98 \\
\hline & 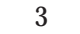 & & - & + & + & - & + & & 2 & 25 & 118 \\
\hline & 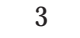 & & - & 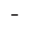 & . & - & - & & 100 & 85 & 100 \\
\hline & . & & - & + & - & - & - & & 95 & 70 & 53 \\
\hline & 3 & & - & - & - & - & + & & 31 & 54 & 100 \\
\hline & 3 & & - & + & - & - & - & - & 100 & 66 & 95 \\
\hline & 3 & & - & + & - & - & - & & 100 & 99 & 93 \\
\hline & 3 & & - & & - & - & + & & 76 & 16 & 96 \\
\hline & 3 & & + & - & - & - & + & & 83 & 41 & 100 \\
\hline & 3 & & + & + & - & - & 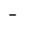 & & 100 & 3 & 100 \\
\hline & 3 & & - & & - & - & - & & 93 & 63 & 61 \\
\hline & 3 & & - & 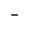 & - & - & - & & 99 & 81 & 93 \\
\hline & 3 & & - & + & - & - & + & & 6 & 79 & 101 \\
\hline & 3 & & - & + & - & - & + & & 59 & 57 & 84 \\
\hline JFV & 3 & iro & + & & 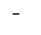 & - & + & & 63 & 22 & 99 \\
\hline
\end{tabular}

testados foram cultivados, por $48 \mathrm{~h}$ sob agitação, em meio King B e, como controle, o mesmo microrganismo foi cultivado no mesmo meio acrescido com $2 \mathrm{iM} \mathrm{.} \mathrm{mL}{ }^{-1}$ de Fe ${ }^{++}$preparado a partir de $\mathrm{FeSO}_{4} 7 \mathrm{H}_{2} \mathrm{O}$, esterilizado por filtração. A mudança de cor do sobrenadante após adição do indicador de azulada para amarelo-avermel hado num prazo de 15 min foi interpretada como indicativa da produção de sideróforos pela bactéria.

Testes de antibiose por dupla camada.

A ntagonistas foram semeados, em pontos eqüidistantes, na superfície do meio 523, em placas de Petri de $9 \mathrm{~cm}$ de diâmetro, seguindo-se a incubação por $24 \mathrm{~h}$ a $28^{\circ} \mathrm{C}$. Decorrido este período,
Tabela 3 - Potencialidade antagonística exibida pelos agentes de biocontrole investigados, em que se detectam a habilidade constitutiva de acionamento de certos mecanismos de antagonismo, independentemente da presença de patógenos

\begin{tabular}{|c|c|c|c|c|c|c|c|c|}
\hline \multirow[t]{2}{*}{$\begin{array}{l}\text { A gentes de } \\
\text { Biocontrole }\end{array}$} & \multirow[t]{2}{*}{ Tipo } & \multirow[t]{2}{*}{$\begin{array}{l}\text { Planta } \\
\text { Alvo }\end{array}$} & \multicolumn{6}{|c|}{$\begin{array}{c}\text { M ecanismos de antagonismo } \\
\text { investigados }(a, b)\end{array}$} \\
\hline & & & 1 & 2 & 3 & 4 & 5 & 6 \\
\hline UFV-BF002 & 1 & Tomateiro & + & - & + & - & + & - \\
\hline UFV-BF017 & 1 & Tomateiro & + & - & + & - & + & + \\
\hline UFV-BF022 & 1 & Tomateiro & + & + & + & + & + & - \\
\hline UFV-BF076 & 1 & Tomateiro & + & + & + & + & + & - \\
\hline UFV-BF 110 & 1 & Tomateiro & + & - & - & - & + & + \\
\hline UFV-BF 114 & 1 & Tomateiro & - & - & - & + & + & - \\
\hline UFV-BF 125 & 1 & Tomateiro & + & - & - & + & + & - \\
\hline UFV-BF 182 & 1 & Tomateiro & + & - & - & + & + & + \\
\hline UFV-BF76B & 1 & Tomateiro & - & - & - & + & - & - \\
\hline UFV-BF04 & 1 & Tomateiro & - & - & - & - & + & - \\
\hline UFV-BF 112 & 1 & Tomateiro & - & - & - & - & + & - \\
\hline UFV-BF $113 C$ & 1 & Tomateiro & - & - & - & - & + & - \\
\hline UFV- RP053 & 3 & Feijoeiro & + & - & + & - & - & + \\
\hline UFV-IEA 06 & 2 & Tomateiro & - & - & - & - & - & + \\
\hline UFV-075 & 2 & Feijoeiro & - & + & + & + & - & + \\
\hline UFV-RD 01 & 1 & Tomateiro & + & + & + & + & + & + \\
\hline UFV-SON 17 & 2 & Tomateiro & - & + & + & + & + & - \\
\hline UFV-A 058R & 1 & Tomateiro & - & + & + & - & + & + \\
\hline UFV-A 062R & 1 & Tomateiro & - & - & + & + & + & + \\
\hline UFV-A 064R & 1 & Tomateiro & + & - & + & - & + & + \\
\hline UFV-A 067R & 1 & Tomateiro & - & + & - & - & + & + \\
\hline UFV-A 092R & 1 & Tomateiro & - & + & + & - & + & + \\
\hline UFV-A 094R & 1 & Tomateiro & + & + & + & - & + & - \\
\hline UFV-A 097R & 1 & Tomateiro & + & + & + & + & + & - \\
\hline UFV-A 098R & 1 & Tomateiro & - & + & + & - & + & + \\
\hline UFV-A 479R & 1 & Tomateiro & + & - & - & - & + & + \\
\hline UFV-B 006R & 3 & Tomateiro & + & + & + & + & - & + \\
\hline UFV-B 023R & 3 & Tomateiro & + & + & + & + & - & - \\
\hline UFV-B 026R & 3 & Tomateiro & - & - & + & + & - & + \\
\hline UFV-B 101R & 3 & Tomateiro & + & - & + & + & - & + \\
\hline UFV-B 182R & 3 & Tomateiro & + & - & + & + & - & + \\
\hline UFV-B 205R & 3 & Tomateiro & + & + & - & + & - & + \\
\hline UFV-B 212R & 3 & Tomateiro & + & - & + & - & - & + \\
\hline UFV-B 224R & 3 & Tomateiro & + & - & - & - & - & + \\
\hline UFV-B 235R & 3 & Tomateiro & + & . & + & + & - & + \\
\hline UFV-B 256R & 3 & Tomateiro & + & - & + & + & - & + \\
\hline UFV-B 268R & 3 & Tomateiro & - & - & - & + & - & + \\
\hline UFV-B 302R & 3 & Tomateiro & - & - & + & + & - & - \\
\hline UFV-B 316R & 3 & Tomateiro & + & - & - & - & + & + \\
\hline UFV-B 322R & 3 & Tomateiro & + & . & + & - & - & + \\
\hline UFV-B 403R & 3 & Tomateiro & + & - & + & - & - & + \\
\hline UFV-B 412R & 3 & Tomateiro & + & - & + & + & - & + \\
\hline UFV-B 423R & 3 & Tomateiro & - & - & - & - & + & + \\
\hline
\end{tabular}

(a) - Mecanismos de antagonismo: $1=$ Sideróforos; $2=\mathrm{HCN} ; 3=\mathrm{NH}_{4}^{+}$; $4=$ Quitinases; $5=$ Celulases e $6=$ Colonização de raízes

(b) - Detectada a produção (+) ou ausência dela (-)

colônias surgidas foram expostas a vapor de clorofórmio por 20 minutos para matar as bactérias e, após volatilização, cada placa recebeu sobre-camada de meio semi-sólido fundente ao qual $100 \mathrm{~mL}$ de suspensão de propágulos do antagonista eram incorporados (22). 0 diâmetro de halos de inibição, quando existentes, era medido.

I nibição de crescimento micelial, por pareamento de culturas.

Placas de Petri contendo meio de cultura adequado ao crescimento do fungo fitopatogênico e do procariota possível antagonista foram preparadas. A ssepticamente, com furador de rolhas, retirou-se um disco $(0,5 \mathrm{~cm}$ de diâmetro) de micélio de uma placa onde o fungo estava em ativo crescimento, disco este que foi depositado na superfície 
Tabela 4 - Teste de antagonismo, pela técnica de dupla camada, realizado com os agentes de biocontrole investigados, contra algumas bactérias fitopatogênicas

\begin{tabular}{|c|c|c|c|c|c|c|}
\hline \multirow[t]{2}{*}{$\begin{array}{l}\text { A gentes de } \\
\text { Biocontrole }\end{array}$} & \multirow[t]{2}{*}{ Tipo } & \multirow[t]{2}{*}{$\begin{array}{l}\text { Planta } \\
\text { Alvo }\end{array}$} & \multicolumn{4}{|c|}{$\begin{array}{l}\text { Patógenos testados } \\
(\mathrm{a}, \mathrm{b})\end{array}$} \\
\hline & & & $\mathrm{G}$ & $\mathrm{H}$ & 1 & 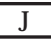 \\
\hline UFV-BF002 & 1 & Tomateiro & 0,4 & 0,0 & 0,0 & 0,0 \\
\hline UFV-BF 017 & 1 & Tomateiro & 0,2 & 0,0 & 0,0 & 0,0 \\
\hline UFV-BF 022 & 1 & Tomateiro & 0,0 & 0,4 & 0,0 & 0,0 \\
\hline UFV-BF076 & 1 & Tomateiro & 0,0 & 0,6 & 1,1 & 0,0 \\
\hline UFV-BF 110 & 1 & Tomateiro & 0,3 & 0,5 & 0,0 & 0,0 \\
\hline UFV-BF 114 & 1 & Tomateiro & 0,4 & 0,0 & 0,0 & 0,0 \\
\hline UFV-BF 125 & 1 & Tomateiro & 0,0 & 0,0 & 0,0 & 0,0 \\
\hline UFV-BF 182 & 1 & Tomateiro & 0,2 & 0,3 & 0,0 & 0,0 \\
\hline UFV-BF76B & 1 & Tomateiro & 0,0 & 0,4 & 0,0 & 0,6 \\
\hline UFV-BF04 & 1 & Tomateiro & 0,4 & 0,6 & 0,0 & 0,0 \\
\hline UFV-BF 112 & 1 & Tomateiro & 0,0 & 0,6 & 0,3 & 0,0 \\
\hline UFV-BF $113 C$ & 1 & Tomateiro & 0,7 & 0,8 & 0,6 & 0,0 \\
\hline UFV- RP053 & 3 & Feijoeiro & 1,2 & 1,1 & 0,9 & 0,0 \\
\hline UFV-IEA 06 & 2 & Tomateiro & 0,2 & 0,0 & 0,0 & 0,0 \\
\hline UFV-075 & 2 & Feijoeiro & 0,0 & 0,0 & 0,0 & 0,0 \\
\hline UFV-RD 01 & 1 & Tomateiro & 0,0 & 0,0 & 0,0 & 0,0 \\
\hline UFV-SON 17 & 2 & Tomateiro & 0,0 & 0,0 & 0,0 & 0,0 \\
\hline UFV-A 058R & 1 & Tomateiro & 0,5 & 1,3 & 0,4 & 0,0 \\
\hline UFV-A 062R & 1 & Tomateiro & 0,0 & 0,0 & 0,0 & 0,0 \\
\hline UFV-A 064R & 1 & Tomateiro & 0,0 & 0,0 & 0,0 & 0,0 \\
\hline UFV-A 067R & 1 & Tomateiro & 0,0 & 1,0 & 0,0 & 0,0 \\
\hline UFV-A 092R & 1 & Tomateiro & 0,5 & 0,0 & 0,0 & 0,7 \\
\hline UFV-A 094R & 1 & Tomateiro & 0,0 & 0,0 & 0,0 & 0,3 \\
\hline UFV-A 097R & 1 & Tomateiro & 0,0 & 0,5 & 0,0 & 0,0 \\
\hline UFV-A 098R & 1 & Tomateiro & 0,3 & 0,0 & 0,0 & 0,0 \\
\hline UFV-A 479R & 1 & Tomateiro & 0,3 & 0,8 & 0,0 & 0,0 \\
\hline UFV-B 006R & 3 & Tomateiro & 0,6 & 0,0 & 0,4 & 0,0 \\
\hline UFV-B 023R & 3 & Tomateiro & 0,0 & 0,0 & 0,3 & 0,0 \\
\hline UFV-B 026R & 3 & Tomateiro & 0,5 & 0,0 & 0,0 & 0,0 \\
\hline UFV-B 101R & 3 & Tomateiro & 0,0 & 0,3 & 0,0 & 0,0 \\
\hline UFV-B 182R & 3 & Tomateiro & 0,0 & 0,0 & 0,0 & 0,4 \\
\hline UFV-B 205R & 3 & Tomateiro & 0,0 & 0,0 & 0,0 & 0,0 \\
\hline UFV-B 212R & 3 & Tomateiro & 0,2 & 0,5 & 0,7 & 0,5 \\
\hline UFV-B 224R & 3 & Tomateiro & 0,2 & 0,0 & 0,0 & 0,0 \\
\hline UFV-B 235R & 3 & Tomateiro & 0,0 & 0,0 & 0,6 & 0,0 \\
\hline UFV-B 256R & 3 & Tomateiro & 0,0 & 0,0 & 0,8 & 0,4 \\
\hline UFV-B 268R & 3 & Tomateiro & 0,0 & 0,0 & 0,0 & 0,0 \\
\hline UFV-B 302R & 3 & Tomateiro & 0,0 & 0,0 & 0,0 & 0,0 \\
\hline UFV-B316R & 3 & Tomateiro & 0,0 & 0,0 & 0,0 & 0,0 \\
\hline UFV-B 322R & 3 & Tomateiro & 0,3 & 0,0 & 0,4 & 0,6 \\
\hline UFV-B 403R & 3 & Tomateiro & 0,0 & 0,0 & 0,0 & 0,0 \\
\hline UFV-B 412R & 3 & Tomateiro & 0,2 & 0,0 & 0,5 & 0,0 \\
\hline UFV-B 423R & 3 & Tomateiro & 0,0 & 0,0 & 0,0 & 0,0 \\
\hline
\end{tabular}

(a) Patógenos: $A=$ Ralstonia solanacearum; $B=$ Erwinia carotovora subsp. carotovora, $C=$ Clavibacter michiganensis subsp. michiganensis, $\mathrm{D}=$ Xanthomonas campestris $\mathrm{pv}$. vesicatoria

(b) Valores referem-se ao diâmetro, em centímetros, do halo de inibição observado

do meio da placa de bioensaio, próximo do bordo. Com alça de repicagem, depositou-se uma gota de cultura em meio líquido do antagonista, na fase logarítmica de crescimento, num ponto diametralmente oposto àquele onde o disco de micélio foi colocado. Placas foram incubadas em condições ideais para o crescimento de ambos os componentes microbianos da interação e examinadas periodicamente. Em caso de inibição, o micélio exibia dificuldade de expandir-se na direção da colônia do antagonista.

I nibição da germinação de conídios.

Preparou-se suspensão de esporos do fungo e ajustou-se a concentração de conídios para $5 \times 10^{4}$ esporos $/ \mathrm{mL}$, ao hemacitômetro e suspensão de propágulos do procariota antagonista, na fase exponencial de crescimento, por turbidimetria para $O D_{540}=0,1$. Foi utilizado a técnica de lâmina escavada, quando misturaram-se volumes iguais das duas suspensões, seguindo-se incubação, procedendo à contagem de um total de 200 esporos, considerando como germinados, os conídios que apresentaram o comprimento do tubo germinativo maior que a metade da extensão do conídio.

Produção de amônia.

Os antagonistas foram cultivados em caldo nutritivo por $72 \mathrm{~h}$ quando foi adicionado ao meio o reativo de $N$ essler em igual volume de meio. A formação de um precipitado de coloração amarelada indicou a produção de amônia pelo isolado.

\section{RESULTADOS E DISCUSSÃO}

Dos agentes de biocontrole investigados (Tabela 1) quanto à sua potencialidade antagonística, somente al guns foram identificados em nível de gênero ou espécie: UFV-B 101, U FV-B 212, U FV-IEA 06, UFV-75 (Bacillus cereus); UFV-B 268, (Streptomyces sp.); UFVRP053 (P seudomonas putida biotipo B); UFV-RD01 (Streptomyces setoni); U FV-SON 017 (N ocardioides thermolilacinus). Será ef etuada, posteriormente, a identificação dos demais agentes de biocontrole aqui investigados.

Conforme explicitam os dados (Tabela 2), os agentes de biocontrole inibiram crescimento micelial e germinação de conídios de fungos de forma variável e sem especificidade no sentido em que agentes de biocontrole isolados de tomateiro inibiram patógenos de feijoeiro e vice-versa, mas vale ressaltar que o isolamento U FV- R P053 (P seudomonas putida), autóctone em rizosfera de feijoeiro, mostrouse capaz de inibir todos os patógenos em todos os testes realizados.

Q uando se atenta para os resultados (Tabela 3), constata-se que a potencialidade antagonística foi também variável e carente de especificidade. Quando a produção de substâncias antimicrobianas hidrossolúveis foi investigada (Tabela 4), constatou-se que poucos antagonistas não foram capazes de inibir o crescimento de pelo menos uma das fitobactérias testadas.

E speradamente, todos os agentes de biocontrole exibiram al gum tipo de antagonismo contra pelo menos um dos patógenos em estudo. O s dados apresentados (Tabela 2, 3 e 4) não permitem inferências sobre a natureza do mecanismo de antagonismo investigado no que tange ser el e constitutivo ou induzível mesmo porque não era esse o objetivo primordial do estudo. A lguns testes como produção de sideróforos, $\mathrm{HCN}$; amônia, quitinases e celulases foram realizados na ausência de patógenos e parece que são constitutivos. Outros, envolvendo a presença do patógenos como indicadores, a exemplo do pareamento de culturas, germinação de conídios e antibiose pela técnica de dupla camada podem ser constitutivos ou induzíveis.

Conforme mostrado (Tabela 2 e 4), os testes de antibiose "in vitro" pela técnica de dupla camada e de pareamento de culturas permitem detectar se 0 antagonista sintetiza substâncias capazes de inibir o crescimento e, ou, multiplicação do patógeno. Poucos dos antagonistas selecionados deixaram de inibir pelo menos um dos patógenos investigados. Produção de substâncias antimicrobianas é um mecanismo universal de antagonismo e agentes de biocontrole 0 exibem com freqüência, ainda que necessariamente não sejam os únicos nem os mais importantes.

Colonização de raízes é um fenômeno que pode ser interpretado como sendo também de antagonismo por competição e poucos dos antagonistas autóctones de rizosfera ou rizoplano deixaram de fazê- 
lo, dentro das limitações do teste idealizado por Silva et al. (25) conforme os dados (Tabela 4). $N$ a verdade, este tipo de estudo verifica, ainda que de forma indireta, a habilidade de rizobactérias quanto à ocupação-exclusão de nichos ecológicos e competição por nutrientes.

Pelo exame (Tabela 4), observa-se que tanto rizobactérias como residentes de filoplano produziram, em sua maioria, sideróforos. Esses compostos estão sabidamente envolvidos no biocontrole (2).

A maioria dos antagonistas foi capazes de produzir quitinases ou celulases ou ambas (Tabela 4). Já é fato estabelecido que enzimas, principalmente os líticos, como quitinases, celulases e glucanases, sejam sintetizados por microrganismos também como mecanismos de antagonismo (5) e que, em muitas situações, esse mecanismo pode explicar, pelo menos em parte, o controle biológico de enfermidades de plantas promovido por alguns agentes procariotas.

Há muito se sabe que microrganismos produzem substâncias voláteis capazes de inibir o crescimento e, ou, a multiplicação de outros microrganismos (14). Em termos de ecologia microbiana, isto é, e pode ser visualizado como, um mecanismo de antagonismo. Os dados mostram (Tabela 4) que se investigou a produção de $\mathrm{HCN}$ e amônia pelos antagonistas e que muitos deles produziam um, outro ou ambos os compostos.

No que tange à germinação de conídios de fitopatógenos, a observação dos resultados (Tabela 3), permite-nos inferir que esta habilidade é comum a quase todos os antagonistas, no caso de pelo menos um dos fungos investigados. Realmente, muitos agentes procarióticos de controle biológi co são capazes de exercer antagonismo diretamente contra patógenos de plantas, inibindo a germinação de seus propágulos. D entre os diversos mecanismos de controle biológico, antagonismo direto é um dos que são sempre considerados (8) e, geral mente, isso pode acontecer graças à produção de substâncias que inibem, de alguma forma, a germinação de unidades propagativas de patógenos fúngicos.

Esses agentes de biocontrole foram selecionados dentre milhares de isolamentos obtidos, principalmente por sua capacidade de promover controle biológico por indução de resistência $(3,9,15$, $16,27)$. 0 fato de eles exibirem atividade de antagonismo contra fitopatógenos e o significado biológico desta constatação podem ser atribuíveis a diferentes causas. Primeiramente, pode ser que el es atuem como agentes de controle biológico por indução de resistência e que a potencialidade antagonística expressada se constitua em um artefato observável "in vitro" mas sem significância "in vivo". Há, inclusive, relatos fal ando da inadequação do uso de testes antagonismo "in vitro" apenas como método de sel eção de agentes de controle biológico (10, 17). E m contraposição, talvez o controle biológico observado, quando da seleção desses agentes, se deva tanto a indução de resistência como a antagonismo direto.

Em qual quer instância, é importante que se conheça com mais detalhes o perfil de potencialidade antagonística dos agentes de biocontrole já selecionados e existentes no LBPCB (Laboratório de B acteriologia de Plantas e Controle Biológico) do Departamento de Fitopatologia da UFV quer para pesquisas mais detalhadas com biocontrole no futuro quer para o desenvolvimento de bioprodutos e, ou biopesticidas.

\section{RERERÊNCIASBIBLIOGRÁFICAS}

1. Bashan, $Y$. Inoculants of plant growth-promoting bacteria for use in A griculture. Biotechnology Advances, Oxford, v.16, n.4, p.729-770, 1998.

2. Bloemberg, G.V.; Lugtenberg, B.J.J. Molecular basis of plant gro- wth promotion and biocontrol by rhizobacteria. Current 0 pinion in Plant Biology, Oxford, v.4, n.4, p.343-350, 2001.

3. Carrer Filho, R. Actinomicetos como agentes de biocontrole de doenças e como promotores de crescimento do tomateiro. 2002. 78F. Tese (M estrado em Fitopatologia) - Departamento de Fitopatologia, Universidade Federal de Viçosa, Viçosa.

4. Castric, K.F.; Castric, P.A. M ethod for rapid detection of cyanogenic bacteria. Applied and Environmental Microbiology, Birmingham, v.45, n.2, p.701-702, 1983.

5. Duffy, B.; Schouten, A.; Raaijmakers, J.M. Pathogen self-defense: mechanisms to counteract microbial antagonism. Annual Review of Phytopathology, Palo Alto, v.41, p.501-538, 2003.

6. Feigl, F.; A nger, V. Replacement of benzidine by cooper ethylacetoacetato and tetrabase as spot-test reagent for hydrogen cyanide and cyanogen. Analyst, London, v.91, p.282-284, 1966.

7. Gerhardt, P.; M urray, R.G.E.; Wood, W.A.; K rieg, N.R.E. M ethods for General and Molecular Bacteriology. 2.Ed. Washington, DC: A merican Society for M icrobiology, 1994. 791p.

8. Guetsky, R.; Shtienberg, D.; Elad, Y.; Fischer, E.; Dinoor, A. Improving biological control by combining biocontrol agents each with several mechanisms of disease suppression. Phytopathology, Saint Paul, v.92, n.9, p.976-985, 2002.

9. Halfeld-Vieira, B.A. Bactérias residentes de filoplano do tomateiro como agentes de controle biológico de enfermidades da parte aérea da cultura. 2002. 98f. Tese (Doutorado em Fitopatologia) - Departamento de Fitopatologia, Universidade Federal de Viçosa, Viçosa.

10. Halfeld-Vieira, B.A.; Romeiro, R.S.; M izubuti, E.S.G. Evidências da inadequação de testes de antibiose como critério para a seleção de bactérias do filoplano como agentes de controle biológico. In: A nais do Congresso Brasileiro de Fitopatologia, 36., 2003, U berlândia. XXXVI Congresso Brasileiro de Fitopatologia. Brasília: Sociedade Brasileira de Fitopatologia, 2003. 1 CR-ROM.

11. Kado, C.I.; Heskett, M.G. Selective media for isolation of Agrobacterium, Corynebacterium, Erwinia, Pseudomonas and Xanthomonas. Phytopathology, Saint Paul, v.60, p.969 - 979, 1970.

12. M acagnan, D. I solamento e seleção de bactérias endosporogênicas e do tipo actinomicetos visando o biocontrole da vassoura-de-bruxa (Crinipellis perniciosa) e da podridão-parda (Phytophthora spp.) e estudo dos mecanismos de antagonismo ao fungo Crinipellis perniciosa. 2005. 113f. Tese (Doutorado em Fitopatologia) - Departamento de Fitopatologia, U niversidade Federal de Viçosa, Viçosa.

13. M acagnan, D.; Romeiro, R.S.; Souza, J. T., Pomella, A. W. V. I solation of actinomycetes and endospore-forming bacteria from the cacao pod surface and their activity against the witches' broom and black pod pathogens. Phytoparasitica, R ehovot. v.34, n.1, p.122-132. 2006.

14. Madigan, M.M.; Martinko, J.; Parker, J.E. Brock Biology of M icroorganisms. 10.ed. N ew York: Prentice Hall, 2003. 1104p.

15. M endonça, H.L. Seleção de rizobactérias como promotoras de crescimento e indutoras de resistência sistêmica em feijoeiro. 2006. 63f. Tese (M estrado em Fitopatologia) - Departamento de Fitopatologia, Universidade Federal de Viçosa, Viçosa.

16. Moura, A.B. Actinomicetos como agentes potenciais de controle biológico da murcha bacteriana (Pseudomonas solanacearum) e como promotores de crescimento de tomateiro. 1996. 167f. Tese (Doutorado em Fitopatologia) - Departamento de Fitopatologia, Universidade Federal de Viçosa, Viçosa.

17. Napoleão, R.L.; Romeiro, R. S.; Oliveira, J. R. Considerações sobre a inadequação de testes de antibiose "in vitro" como único método de busca por potenciais procariotas antagonistas a Agrobacterium tumefaciens. Fitopatologia Brasileira, Brasília, v.20, supl., p.374. 1995.(Resumo).

18. Pramer, D.; Schmidt, E.L. Experimental Soil Microbiology. 3.ed. M inneapolis, MN: Burgess Publishing Company, 1964. 430p.

19. Reid, J.D.; Ogrydziak, D.M. Chitinase-overproducing mutant of Serratia marcescens. J ournal of Applied Microbiology, London, v.41, p.664-669, 1981. 
20. Renwick, A.; Campbell, R.; Coe, S. A ssessment of in vitro screening systems for potential biocontrol agents of Gaeumannomyces graminis. Plant Pathology, Oxford, v.40, p.524-532, 1991.

21. Romeiro, R.S.; Garcia, F.A.O. Controle biológico de enfermidades de plantas incitadas por bactérias. Revisão A nual de Patologia de Plantas, Passo Fundo, v.11, p.195-227, 2003.

22. Romeiro, R. S. M étodos em Bacteriologia de Plantas. 1.ed. Viçosa: Editora UFV, 2001. v.1, 279p.

23. Schwyn, B.; Neilands, J.B. Universal chemical assay for the detection and determination of siderophores. Analytical Biochemistry, Oxford, v.160, p.47-56, 1987.

24. Silva, H.S.A. Rizobactérias como promotoras do crescimento de plantas de tomateiro (Lycopersicon esculentum Mill.) e indutoras de resistência sistêmica a patógenos foliares da cultura. 2002. 115f. Tese (Doutorado em Fitopatologia) - De- partamento de Fitopatologia, Universidade Federal de Viçosa, Viçosa.

25. Silva, H.S.A.; Romeiro, R.S.; M ounteer, A. Development of a root colonization bioassay for rapid screening of rhizobacteria for potential biocontrol agents. Journal of Phytopathology, Berlin, v.151, n.1, p.42-46, 2003.

26. Smith, D.; Onions, A.H.S. The preservation and maintenance of living fungi. 2.ed. Wallingford: CA B International, 1994. v.1, 122p.

27. Vieira Júnior, J.R. Procariotas residentes de filoplano do feijoeiro como agentes de biocontrole de enfermidades da parte aérea da cultura. 2005. 146f. Tese (Doutorado em Fitopatologia) - Departamento de Fitopatologia, Universidade Federal de Viçosa, Viçosa. 